\title{
Two-step functional screen on multiple proteinaceous substrates reveals temperature-robust proteases with a broad-substrate range
}

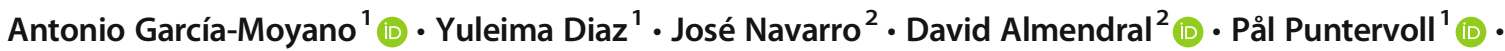 \\ Manuel Ferrer ${ }^{2}$ (D) Gro Elin Kjæreng Bjerga ${ }^{1}$
}

Received: 30 August 2020 / Revised: 15 February 2021 / Accepted: 14 March 2021 / Published online: 26 March 2021

(C) The Author(s) 2021

\begin{abstract}
To support the bio-based industry in development of environment-friendly processes and products, an optimal toolbox of biocatalysts is key. Although functional screen of (meta)genomic libraries may potentially contribute to identifying new enzymes, the discovery of new enzymes meeting industry compliance demands is still challenging. This is particularly noticeable in the case of proteases, for which the reports of metagenome-derived proteases with industrial applicability are surprisingly limited. Indeed, proteolytic clones have been typically assessed by its sole activity on casein or skim milk and limited to mild screening conditions. Here, we demonstrate the use of six industry-relevant animal and plant by-products, namely bone, feather, blood meals, gelatin, gluten, and zein, as complementary substrates in functional screens and show the utility of temperature as a screening parameter to potentially discover new broad-substrate range and robust proteases for the biorefinery industry. By targeting 340,000 clones from two libraries of pooled isolates of mesophilic and thermophilic marine bacteria and two libraries of microbial communities inhabiting marine environments, we identified proteases in four of eleven selected clones that showed activity against all substrates herein tested after prolonged incubation at $55{ }^{\circ} \mathrm{C}$. Following sequencing, in silico analysis and recombinant expression in Escherichia coli, one functional protease, 58\% identical at sequence level to previously reported homologs, was found to readily hydrolyze highly insoluble zein at temperatures up to $50{ }^{\circ} \mathrm{C}$ and $\mathrm{pH} 9-11$. It is derived from a bacterial group whose ability to degrade zein was unknown. This study reports a two-step screen resulting in identification of a new marine metagenome-derived protease with zein-hydrolytic properties at common biomass processing temperatures that could be useful for the modern biorefinery industry.
\end{abstract}

\section{Key points}

- A two-step multi-substrate strategy for discovery of robust proteases.

- Feasible approach for shortening enzyme optimization to industrial demands.

- A new temperature-tolerant protease efficiently hydrolyzes insoluble zein.

Keywords Functional metagenomics $\cdot$ Agar screen $\cdot$ Protease M10/M12 $\cdot$ Zein

\section{Introduction}

The market for novel enzymes and their uses in more environmentally friendly industrial and speciality applications is growing. The global enzyme market is dominated by food and feed

Gro Elin Kjæreng Bjerga

grbj@norceresearch.no

1 NORCE Norwegian Research Centre, Thormøhlens gate 55, 5006 Bergen, Norway

2 Institute of Catalysis, Consejo Superior de Investigaciones Científicas, 28049 Madrid, Spain enzymes (Chapman et al. 2018), including protease/peptidase, amylase, and lipase/esterase enzymes. The protease market was valued at 1700 million US\$ in 2018 and is projected to reach 2630 million US\$ by the end of 2025, growing at a compound annual growth rate (CAGR) of 5.6\% (Global Protease Market Report 2019). Recombinant proteases have been applied in industrial biotechnology for decades, such as in the dairy industry, where recombinant chymosin is used in cheese making (Mistry 2006). Alongside, market growth has been driven by the detergent industry, among others, where proteases have been added as ingredients in "greener» household cleaning products and soaps (Maurer 2004). However, the livestock industry is projected to be one of the drivers of future demands for 
the protease market, particularly in the production of new feed ingredients, such as protein hydrolysates from animal co- or byproducts (e.g., bone, feathers, skin, blood from meat, poultry, and fish filet processing) and vegetable ingredients from corn, wheat, etc. (Philipps-Wiemann 2018). The main protein sources in these by-products are collagen, gelatin, keratin, serum albumins and globulins, zein, glutenin, and gliadin, respectively. Some of these sources are known to be recalcitrant and poorly soluble, and the lack of suitable enzymes have limited their application as functional food or feed ingredients (Kong et al. 2007; Anderson and Lamsal 2011; Pal and Suresh 2016; Li 2019). Zein, for example, contains more than $50 \%$ hydrophobic amino acids, likely creating extensive intermolecular interactions that act as barriers for enzymes to access and hydrolyze the peptide bonds (Anderson and Lamsal 2011). Enzymatic hydrolysis has been shown not only to increase the aqueous solubility of zein (Zhu et al. 2008) and increase its antioxidant and anti-inflammatory activity on endothelial cells and cytotoxic effects on cancer cells (Kong and Xiong 2006; Tang et al. 2010; Jin et al. 2016; Díaz-Gómez et al. 2018; Liang et al. 2018) but also to improve its properties as biological active carrier for encapsulation of bioactive components (Kasaai 2018). To support future demands, advancements of technologies for enzyme discovery are key to accelerate the use of alternative protein sources in feed and food.

The advancement of high-throughput sequencing of metagenomic DNA at gradually declining costs has expanded the knowledge of microbial diversity and made this diversity accessible for studies of novel biocatalysts (Ngara and Zhang 2018). Since most microbes in an environmental sample are expected to be non-cultivable under standard conditions in the lab, clone libraries of environmental DNA are transferred to surrogate bacterial hosts, such as Escherichia coli, and functionally characterized through heterologous expression or sequencing. Functional characterization by screens is a common way to discover new enzymes. Such screens include detection of easy-readable phenotypes from single clones in a reporter assay. Since the first report of enzyme discovery from metagenomes in 1995 (Healy et al. 1995), the development of new ways to screen has been slow (Lee and Lee 2013; Ngara and Zhang 2018) and the fraction of this biodiversity that has been subjected to studies on enzyme discovery remains low (Ferrer et al. 2016). Some of the challenges for the discovery of new industrial enzymes by functional screening of metagenomic libraries include the lack of suitable screens with industry-relevant substrates and industry-mimicking conditions (Morris and Marchesi 2015; Ferrer et al. 2016). The classical protease-positive phenotype sought after in functional screening appears by incubating a clone library on skim milk agar (SMA) or casein-supplemented solid medium and detecting clearing zones around the clone that contains the capacity to hydrolyze the substrate. Although it was previously reported that the SMA screen is not sufficient as a definitive screen to identify proteases (Jones et al. 2007), the number of false positives is typically not exceeding the number of true positive clones. Moreover, the absence of reported false negatives (actual proteolytic clones that respond as negative against milk proteins) and the description of alternatives to overcome the bias, e.g., casein or lactose-free skim milk (Morris et al. 2012), make skim milk and casein remain valid substrates for the initial identification of proteolytic metagenomic clones.

In spite of an average frequency of about 10 serine proteases per prokaryotic genome (Tripathi and Sowdhamini 2008) and a relative higher mean incidence rate of proteolytic clones in environmental DNA libraries when performing functional screens, compared to other enzyme classes (e.g., lipases/ esterases or glycosidases) (Ferrer et al. 2016), the reports of metagenome-derived proteases are still limited (Kennedy et al. 2011). In comparison, both lipases/esterase and glycosidases have lower estimated incidence rates, but the amount of reports in the literature are several fold more frequent (Ferrer et al. 2016). In fact, the outcome from functional screens for proteases in metagenomic libraries over the past 15 years is limited to 23 active proteases (Table 1) for which $50 \%$ of them belong to the well-known S8 family (subtilisins). The reported proteases are almost exclusively identified by sole screening on casein or skim milk agar and in limited experimental conditions (typically incubation at $30-37{ }^{\circ} \mathrm{C}$ sometimes prolonged to several days). Their utility against other relevant substrates (substrate range) and their biotechnological potential remains ambiguous (Morris and Marchesi 2015). Although several factors may have contributed to the shortage of protease reports, the choice of substrate creates a bias in the selection of the activities of interest. The introduction of a two-step strategy with an initial selection with a general substrate followed by a more specific one is a recommended approach (Ferrer et al. 2016). In fact, the development of multi-substrate approaches applied to functional screening of microbial metagenomes has resulted in highly efficient discovery rates for other enzyme classes (Schückel et al. 2016; Maruthamuthu et al. 2016). However, such approach has not yet been explored for proteases in a systematic manner.

In this study, we aimed at exploiting a new strategy to discover new temperature-robust proteases with broadsubstrate range that may be better fit for industrial applications. In order to achieve that goal, we have introduced a two-step screen procedure: a first screen on the general skim-milk substrate followed by a more targeted parallel screen in an expanded repertoire of industry-relevant substrates and conditions.

\section{Material and methods}

Metagenomic libraries and fosmid clone origin The collection of proteolytic clones originated from 2 mix-genomic and 2 


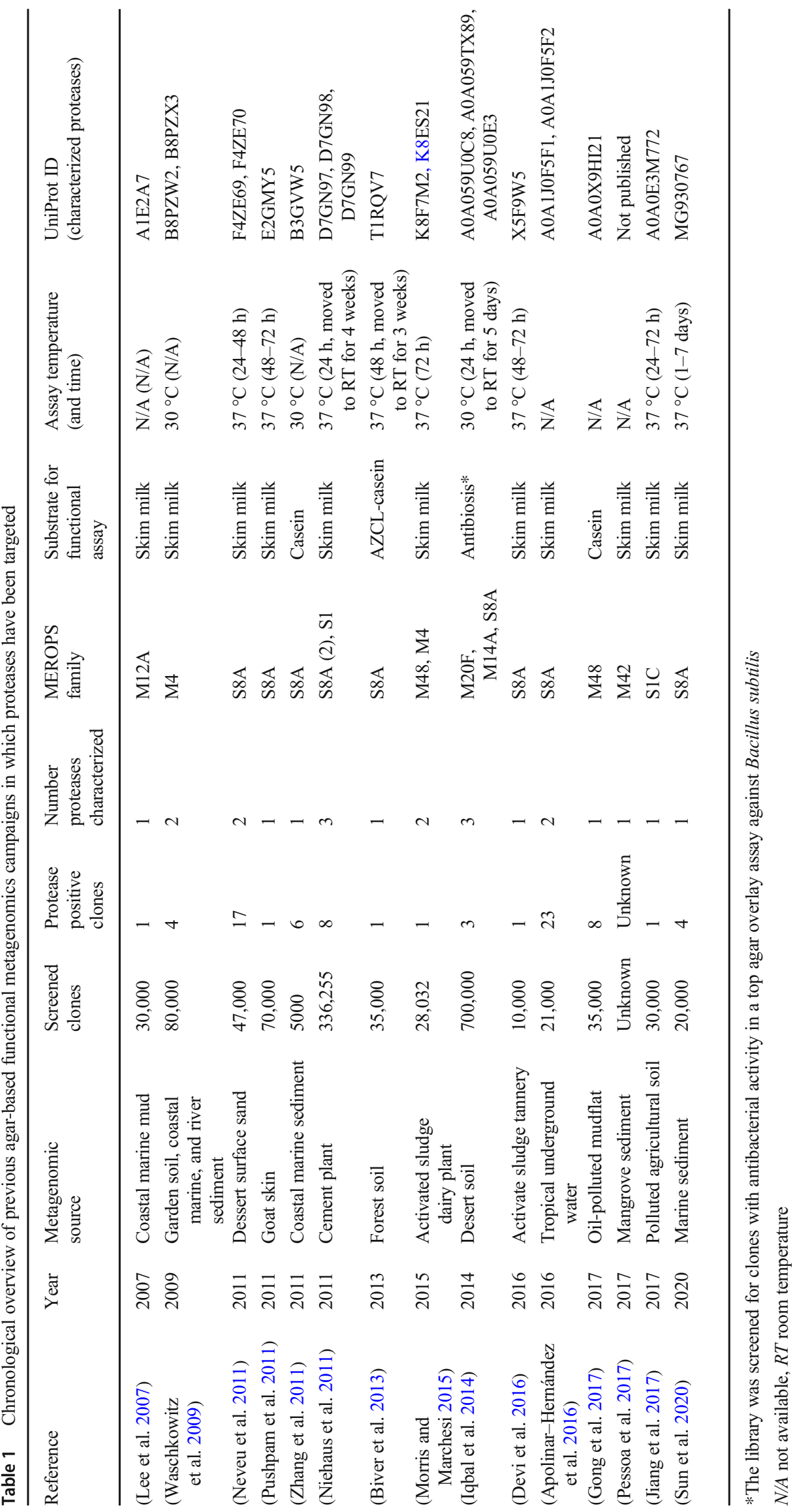


metagenomic libraries, containing unique marine environmental DNA, previously constructed in the pCCFOS1 large insert fosmid vector using the CopyControl fosmid library production kit (Epicentre, USA). They include 2 libraries made from, respectively, 251 thermophilic marine bacterial strains (TB library) and 194 mesophilic marine bacterial strains (MB library) that were isolated from enrichment cultures from deep sea hydrothermal vents and used to prepare "mixed genome" libraries (Leis et al. 2015). Also, two libraries from microbial communities inhabiting the Milazzo polluted harbor (MH libraries) were included, one origining from seawater and one from sediment (Martínez-Martínez et al. 2018). E. coli EPI300-T1 ${ }^{\mathrm{R}}$ (Epicentre, USA) was used as host for all metagenomic libraries.

Multi-substrate functional agar-based screens Fosmid clone libraries were first screened on $22.5 \times 22.5 \mathrm{~cm}$ Petri plates with SMA $(1 \%(\mathrm{w} / \mathrm{v})$ tryptone, $0.5 \%(\mathrm{w} / \mathrm{v})$ yeast extract, and $0.5 \%(\mathrm{w} / \mathrm{v}) \mathrm{NaCl}, 1.5 \%(\mathrm{w} / \mathrm{v})$ agar, and $1 \%(\mathrm{w} / \mathrm{v})$ skim milk (Sigma-Aldrich, USA)) supplemented with L-arabinose $(0.1 \%(\mathrm{w} / \mathrm{v}))$ to induce a high fosmid copy number and 15 $\mu \mathrm{g} / \mathrm{ml}$ chloramphenicol for fosmid selection. Plates were incubated at $37{ }^{\circ} \mathrm{C}$ overnight for microbial growth, and for 3 more days at room temperature to develop putative proteolytic halos. The fosmid clones selected as "proteolytic" based on this classical skim-milk hydrolysis assay were used as a starting point in the multi-substrate screen (Table 2).

This collection of proteolytic clones was propagated and maintained in LB medium $(1 \%(\mathrm{w} / \mathrm{v})$ tryptone, $0.5 \%(\mathrm{w} / \mathrm{v})$ yeast extract, and $0.5 \%(\mathrm{w} / \mathrm{v}) \mathrm{NaCl})$ supplemented with 15 $\mu \mathrm{g} / \mathrm{ml}$ chloramphenicol and $10 \%$ glycerol in 96 deep-well plates. The second multi-substrate functional screens were carried out in peptone-free nutrient agar (NA; $0.3 \%(\mathrm{w} / \mathrm{v})$ yeast extract, $0.5 \%(\mathrm{w} / \mathrm{v}) \mathrm{NaCl}, 1.5 \%(\mathrm{w} / \mathrm{v})$ agar) supplemented with $15 \mu \mathrm{g} / \mathrm{ml}$ chloramphenicol and $0.1 \%$ (w/v) L-arabinose. A double strength solution of temperate NA containing L-arabinose and antibiotic was mixed with the appropriate volume of a set of substrates prepared as follows. A final concentration of $1 \%(\mathrm{w} / \mathrm{v})$ skim milk and $0.04 \%(\mathrm{w} / \mathrm{v})$ cold water fish skin gelatin (Sigma-Aldrich, USA) and $0.5 \%(\mathrm{w} / \mathrm{v})$ blood meal (Giva, Sweden) were respectively added from a sterile stock solution previously autoclaved at $116^{\circ} \mathrm{C}$ for 20 min. An $8 \%(\mathrm{w} / \mathrm{v})$ zein from maize (Sigma-Aldrich, USA) solution was dissolved in $100 \%$ dimethyl sulfoxide (DMSO). Other insoluble substrates such as wheat gluten (Sigma-Aldrich, USA), bone meal (Weibulls, Sweden), and feather meal (Skretting AS, Norway) were directly mixed in the NA solution in parallel. To prevent aggregation of zein, gluten, bone meal, and feather meal when mixed with nutrient agar, the solution was stirred before and during pouring (Wehrle et al. 1999). The NA-substrate solution was topped to $50 \mathrm{ml}$ with pre-warmed $\left(60^{\circ} \mathrm{C}\right)$ sterile water, gently mixed, poured into $12 \times 12 \mathrm{~cm}$ plates, and left to solidify at room temperature. The plates were air-dried inside the laminar flow cabinet before inoculation to avoid condensation droplets that might result in cross-contamination. Inoculation was done manually with a 96-pin replicator in quadruple. Two negative controls consisting of non-proteolytic EPI300-T1 ${ }^{\mathrm{R}}$ candidate clones on skim milk were used. Plates were then incubated upside-down for $14-16 \mathrm{~h}$ at $37{ }^{\circ} \mathrm{C}$ inside a plastic bag to maintain humidity. Development of clearing zone was followed over 2-3 days at room temperature. Temperature screens were assayed with parallel incubations at different temperatures. In this case, two identical plates were inoculated with the collection of proteolytic fosmid clones. Colony growth and clearing zone formation from substrate hydrolysis were registered after an overnight incubation at $37{ }^{\circ} \mathrm{C}$. Subsequently, plates were incubated in parallel for $2-3$ more days at room temperature (approximately $20-22^{\circ} \mathrm{C}$ ) as a gold standard in functional screens and at $55^{\circ} \mathrm{C}$, a typical temperature used during biomass processing, while clearing zone development was monitored. While most of the substrates rendered visible clearing zones in peptone-free medium, feather, bone meal and fish gelatin plates were flooded with Coomassie stain to increase contrast of clearing zones. Plates were then incubated at room temperature during gentle shaking for at least $1 \mathrm{~h}$ or until the first $2-3 \mathrm{~mm}$ agar were densely stained.

Sequencing, annotation, protease candidate selection, and taxonomic assignment The selected clones were grown in $40 \mathrm{ml} \mathrm{LB}$ medium supplemented with $15 \mu \mathrm{g} / \mathrm{ml}$ chloramphenicol at $37{ }^{\circ} \mathrm{C}$ in the absence of high-copy inducer. Cells were pelleted and fosmid DNA isolated with NucleoSpin Plasmid kit (Macherey-Nagen, Germany) following the protocol for low-copy plasmid propagation. After elution, extracts were treated with Plasmid-Safe ATP-dependent DNase (Epicentre, USA) to eliminate genomic DNA that may interfere in the downstream sequencing. Proteolytic EPI300-T1 ${ }^{\mathrm{R}}$ clones were subjected to terminal Sanger sequencing at Secugen (Madrid, Spain). Unique fosmids were then sequenced in pools using a MiSeq Sequencing System (Illumina, San Diego, USA) with a $2 \times 150$-bp sequencing kit. The fosmid metagenomic DNA sequence was submitted to Rapid Annotation using Subsystem Technology (RAST) for gene annotation (Aziz et al. 2008). In parallel, open reading frames (ORFs) were searched by Blast (Altschul et al. 1990) against the MEROPS (Rawlings et al. 2018) and NCBI databases. Sequence identity was noted relative to the closest non-identical sequence. Multiple sequence alignments were built and used to extract positional information of conserved catalytic residues. Pfam (Finn et al. 2014) and CDD (Marchler-Bauer et al. 2011) were used to predict the domain structure. SignalP v4.1 (Nielsen 2017) was used to predict signal peptide sequences. Taxonomic assignment was performed using the MetaErg tool, which classifies all open 


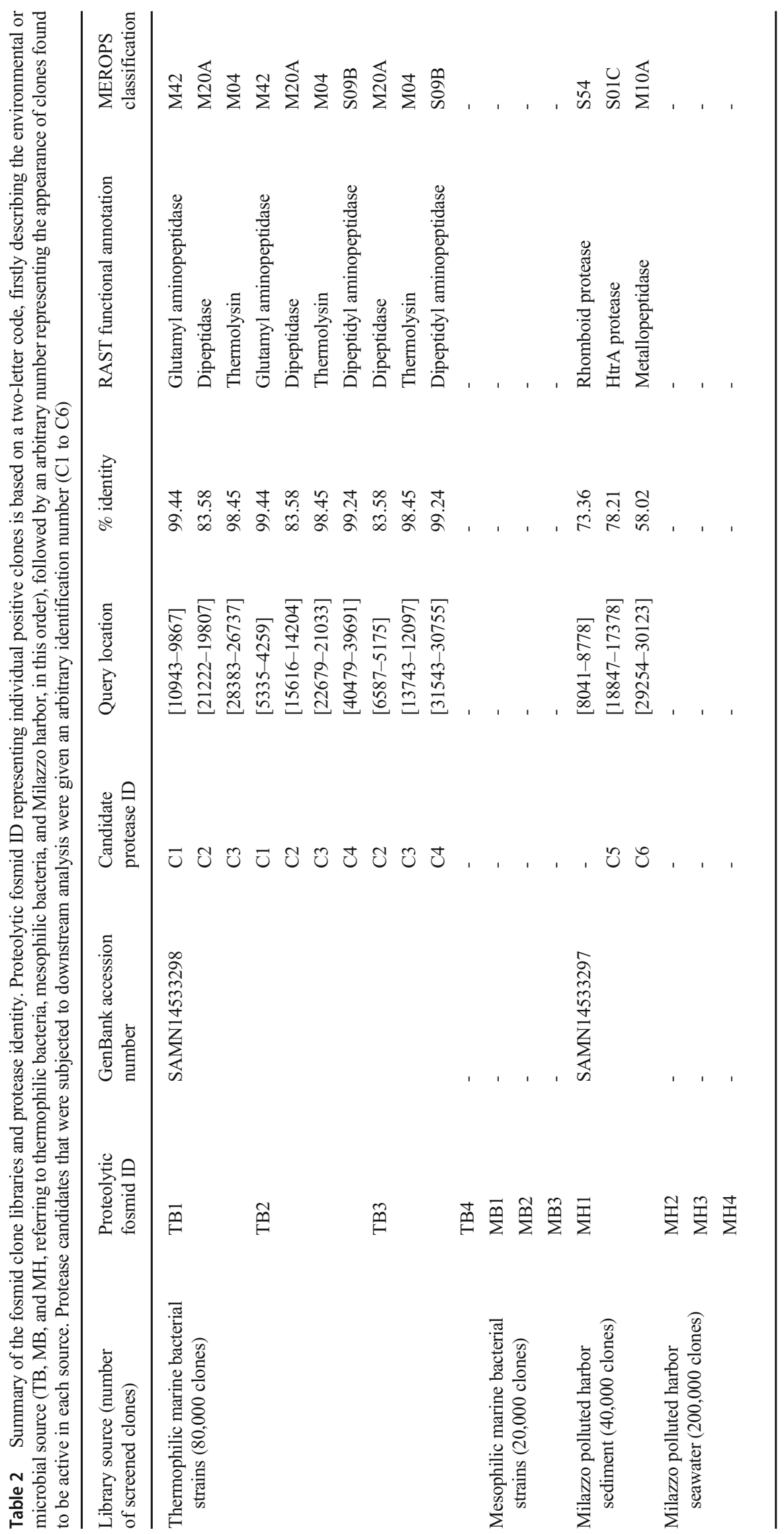


reading frames in a contig based on best DIAMOND hits against a custom database, GenomeDB (Dong and Strous 2019).

\section{Recombinant expression of proteases and functional screen} The candidate protease sequences selected from the proteolytic clones were used as templates for gene synthesis, and genes were codon-optimized by GenScript to maximize expression in E. coli, with the exception of the $\mathrm{C} 6$ candidate. Predicted domain structure was used as a guide for truncations. Genes were flanked by SapI restriction sites and delivered in a customized SapI-free pUC57 plasmid with kanamycin selection marker (GenScript, USA). The encoding DNA sequence for candidate $\mathrm{C} 6$ was PCR-amplified with Phusion High Fidelity DNA polymerase (NEB, UK) from the MH1 fosmid clone, using the SapI sitecontaining primers MH1F 5'-atatatgctcttctagtaaaggcgaaaactacgaccacgatccc-3' and MH1R 5'-tatatagctcttcatgcaacacgtgtctgagtcgeggccgc-3' (restriction sites underlined). The gene fragments were sub-cloned from the delivery vector, or directly from the PCR amplicon in the case of C6, into two expression vectors, $\mathrm{p} 1$ and $\mathrm{p} 12$, supporting arabinose-induced expression of N-terminal and C-terminal histidine (his) fusion proteins, respectively, in E. coli MC1061 (Bjerga et al. 2016). A version of each expression vector, containing a hexapeptidecoding linker (encoding a GSGSGS peptide), was used as background controls. Construction of the expression vectors as well as expression and partial characterization were done as previously described (Bjerga et al. 2016). Following expression, cells were harvested, resuspended in $1 \mathrm{ml}$ lysis buffer $(50 \mathrm{mM}$ Tris $\mathrm{HCl} \mathrm{pH} \mathrm{8.5,} 50 \mathrm{mM} \mathrm{NaCl}, 0.25 \mathrm{mg} / \mathrm{ml}$ lysozyme, $10 \%$ (v/v) glycerol), and sonicated as described above. Cleared lysates were stored at $-20^{\circ} \mathrm{C}$ and used directly for proteolytic activity assessments. Expression and solubility were assessed by TGX precast SDS-PAGE gels in a Mini PROTEAN electrophoresis system (Bio-Rad, Spain). Gels were stained with SimplyBlue SafeStain (Thermo Scientific, USA). The substrate range activity of the recombinant enzymes was analyzed following a similar approach as for the second fosmid clone screen. Plates with the seven different proteinaceous substrates were prepared as described above but supplemented with $100 \mu \mathrm{g} / \mathrm{ml}$ ampicillin and $0.1 \%$ $(w / v)$ L-arabinose. In this case, overnight precultures of both constructs were inoculated in fresh LB medium, grown for $4 \mathrm{~h}$ under constant agitation at $37{ }^{\circ} \mathrm{C}$ followed by induction with $0.1 \%(\mathrm{w} / \mathrm{v})$ L-arabinose for 3 more hours. Inoculation to plates was done with a 96-pin replicator, in triplicates. Plates were incubated for $16-20 \mathrm{~h}$ at $37{ }^{\circ} \mathrm{C}$ for colony development and further overnight at $55^{\circ} \mathrm{C}$ for cell lysis and halo development. Coomassie staining was done as described before for the fish gelatin, feather, and bone meal plates.

Proteolytic activity from cell lysates on zein A mixture


$50 \mathrm{mM} \mathrm{NaCl}, 10 \%$ glycerol $(\mathrm{v} / \mathrm{v})), 1 \mathrm{ml}$ of cell lysate, and
$0.3 \mathrm{~g}$ zein from maize (Sigma-Aldrich, USA) was prepared in $15 \mathrm{ml}$ polyethylene (PE) round-bottom tubes. The tubes were vortexed in order to resuspend the zein powder and incubated at 20 and $50^{\circ} \mathrm{C}$ under constant mixing on a wheel for $48 \mathrm{~h}$. Three replicates per samples were run in parallel. Hydrolysis and solubilization of zein was monitored by detection of TCA-soluble peptides. Standard curve was made with 0 $5.5 \mathrm{mM}$ L-tyrosine (Sigma-Aldrich, USA). Soluble Ltyrosine and L-tryptophan containing zein peptides specifically react with Folin-Ciocalteu reagent (Sigma-Aldrich, USA) to produce a color change with a maximum absorbance at 660 $\mathrm{nm}$. The tubes were centrifuged at $12,000 \times \mathrm{g}$ for $10 \mathrm{~min}$ in order to pellet insoluble proteins. Samples were taken avoiding the top carotenoid-rich layer and further diluted in order to fit within the standard curve range. Measurements were done in triplicate in a Hidex Sense microplate reader (Hidex, Finland).

Purification and characterization of the $\mathrm{C} 6$ protease The histagged C6 protein was expressed in E. coli MC1061. For enzyme production, a single $E$. coli colony, previously grown at $37{ }^{\circ} \mathrm{C}$ on solid LB agar medium supplemented with 100 $\mu \mathrm{g} / \mathrm{ml}$ ampicillin, was picked and used to inoculate $50 \mathrm{ml}$ of LB medium supplemented with $100 \mu \mathrm{g} / \mathrm{ml}$ ampicillin in a $0.25 \mathrm{~L}$ flask, following by cultivation at $37^{\circ} \mathrm{C}$ and $200 \mathrm{rpm}$ overnight. Afterwards, $50 \mathrm{ml}$ of this culture was used to inoculate $1 \mathrm{~L}$ of $\mathrm{LB}$ medium with antibiotic in a $2.5 \mathrm{~L}$ flask, which was incubated to an $\mathrm{OD}_{600 \mathrm{~nm}}$ of approximately 0.7 at $37^{\circ} \mathrm{C}$. Protein expression was induced by adding L-arabinose to a final concentration of $0.1 \%(\mathrm{w} / \mathrm{v})$, followed by incubation for $16 \mathrm{~h}$ at $16{ }^{\circ} \mathrm{C}$. The cells were harvested by centrifugation at $5000 \times g$ for $15 \mathrm{~min}$ to yield a pellet of $2-3 \mathrm{~g}$ (wet weight). The wet cell pellet was frozen at $-80{ }^{\circ} \mathrm{C}$ overnight, thawed and

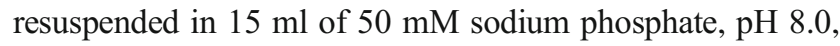
$10 \mathrm{mM}$ imidazole, and $300 \mathrm{mM} \mathrm{NaCl}$. Lysonase Bioprocessing Reagent (Novagen, Germany) was added (4 $\mu \mathrm{l} / \mathrm{g}$ wet cells) and incubated for $60 \mathrm{~min}$ on ice with rotating mixing. The cell suspension was sonicated for a total of $5 \mathrm{~min}$ and centrifuged at $15,000 \times g$ for $15 \mathrm{~min}$ at $4{ }^{\circ} \mathrm{C}$, and the supernatant was retained. The soluble His-tagged protein was purified at $4{ }^{\circ} \mathrm{C}$ by affinity chromatography in Ni-NTA HisBind (Sigma-Aldrich, USA) and elution with $50 \mathrm{mM}$ sodium phosphate $\mathrm{pH} 8.0,250 \mathrm{mM}$ imidazole, and $300 \mathrm{mM} \mathrm{NaCl}$. Eluted protein was subjected to ultra-filtration through lowadsorption hydrophilic 10,000 nominal molecular weight limit cut-off regenerated cellulose membranes (Amicon, USA) to concentrate the protein solution. An extensive dialysis of protein solutions against $40 \mathrm{mM}$ 4-(2-hydroxyethyl)-1piperazineethanesulfonic acid (HEPES) buffer $\mathrm{pH} 7.0$ was performed using Pur-A-LyzerTM Maxi 1200 dialysis kit (Sigma-Aldrich, USA), as follows; $5 \mathrm{ml}$ concentrated protein solution was dialyzed against $2 \mathrm{~L}$ buffer during $1 \mathrm{~h}$ at room temperature, after which the buffer was changed by other $2 \mathrm{~L}$ 
buffer and maintained $1 \mathrm{~h}$ more. Then, the buffer was changed and the dialysis was kept overnight at $4{ }^{\circ} \mathrm{C}$. The dialyzed protein solution was recovered and concentrated as before. Purity was assessed as $>98 \%$ using SDS-PAGE analysis in a Mini PROTEAN electrophoresis system (Bio-Rad, Spain). A total of about $4.6 \mathrm{mg}$ total purified recombinant protein was obtained from $1 \mathrm{~L}$ culture.

Optimal pH of the $\mathrm{C} 6$ candidate was studied in $50 \mathrm{mM}$ Britton-Robinson buffer at $50^{\circ} \mathrm{C}$, as follows. A stock solution of $10 \%$ zein (Sigma Aldrich, USA) was prepared in DMSO. To a total of $200 \mu \mathrm{l}$ of buffer at the desired $\mathrm{pH}, 10 \mu \mathrm{l}$ of the zein stock solution and $2 \mu \mathrm{l}$ of a stock solution of purified recombinant C6 $(30 \mathrm{mg} / \mathrm{ml})$ were added. Triplicate reactions and a control without enzyme were maintained for $2 \mathrm{~h}$ at 50 ${ }^{\circ} \mathrm{C}$. Hydrolysis of zein was monitored by detection of Ltyrosine at $492 \mathrm{~nm}$ using the Tyrosine Assay Kit (SigmaAldrich, USA). For temperature optima determination, $50 \mathrm{mM}$ Britton-Robinson buffer $\mathrm{pH} 10.0$ and a temperature range from 20 to $70{ }^{\circ} \mathrm{C}$ were set up. Zein hydrolysis was monitored, in triplicates with control reactions, at the indicated temperatures for $24 \mathrm{~h}$ using the L-tyrosine detection assay kit. Measurements were done in a Synergy HT Multi-Mode Microplate Reader (Bio Tek, USA).

\section{Results}

\section{Identification of proteolytic enzymes in a two-step functional screen}

To identify new proteases from uncultured microbes of environmental metagenomes, we screened four DNA libraries (in the host $E$. coli) containing genomic DNA derived from mix culture collections of marine mesophilic and thermophilic bacteria and uncultured microbial communities inhabiting marine water samples and sediments from Milazzo harbor. Libraries were selected, among a total of about 30 existing clone libraries from microbial communities inhabiting 28 geographically distinct environmental sites, based on broad diversity and high enzyme discovery rates (Leis et al. 2015; Popovic et al. 2017; Martínez-Martínez et al. 2018). The libraries were firstly screened on solid medium for their capacity to hydrolyze skim milk (first screen). In total, 11 proteolytic clones were identified in a total of 340,000 clones tested (Table 2). These served as the starting material for the assessment of new functional screens based on other proteinaceous substrates (second multi-substrate screen).

\section{Parallel multi-substrate screen at elevated tempera- ture confirmed relevant proteolytic clones}

We performed several functional agar-based assays using a number of substrates to identify industry-relevant protease candidates with a broad-substrate scope. In addition to skim milk, seven proteinaceous substrates were selected that included fish gelatin, zein, gluten, bone meal, feather meal, and blood meal. Although some of the insoluble substrates (zein, gluten, bone meal, and feather meal) remained visible on the plates as small agglomerates, stirring resulted in a homogeneous dispersion of the particles, allowing detection of hydrolysis.

The eleven proteolytic fosmid clones that were identified during the first screen step on skim milk were tested for activity against the seven proteinaceous substrates in a second screen step. Two parallel experiments were performed for each substrate by overnight colony growth at $37^{\circ} \mathrm{C}$ on solid media followed by up to $72 \mathrm{~h}$ incubation at two temperature conditions: one parallel at $20^{\circ} \mathrm{C}$ as a standard for functional metagenomic surveys (Table 1) and another parallel at $55^{\circ} \mathrm{C}$, as a common temperature for industrial protein hydrolysis. At the end of the experiment, clearing zone formation, indicating proteolytic activity, was registered and all eleven proteolytic fosmid clones showed reproducible hydrolysis against skim milk (Table 3). Four of the clones, TB1, TB2, TB3, and MH1, showed proteolytic activity against all seven substrates tested. Eight clones showed activity in at least one of the other six substrates, while three clones, MB1, MH3, and MH4, did not show activity against any other substrate. Interestingly the four clones that showed activity against all substrates (MH1, TB1, TB2, and TB3) generated a larger clearing zone after incubation at $55^{\circ} \mathrm{C}$ than at $20^{\circ} \mathrm{C}$ (Fig. 1). This suggests that they may encode one or more thermophilic/thermostable proteases, which is supported by the fact that these clones originated from metagenomes from mixed mesophilic (MH1) or thermophilic (TB1, TB2, TB3) bacterial strains. Due to their broad-substrate range and potential thermostability, these four clones were selected for sequencing of their metagenomic DNA.

\section{Metagenomic DNA of the four clones with broad- substrate range contained 6 putative proteases}

Sequencing and annotation of the DNA insert regions revealed that the TB1, TB2, and TB3 clones, which appeared to be active on zein only at $55^{\circ} \mathrm{C}$, contained partially overlapping and identical sequence regions. Their sequences form a single contig (51144 bp length) encoding altogether four candidate protease sequences, two of which are shared among all three clones (Table 2, Table S1). The MH1 clone which appeared to be active on zein at both temperatures tested, but with increased activity at elevated temperatures, contained unique DNA encoding three proteases (Table 2, Table S1). The predicted S54 rhomboid peptidase identified in the clone MH1 was dismissed due to their membrane-associated character and thus lack of industrial compliancy. To conclude, 6 unique putative proteases encoding genes were investigated. 
Table 3 Summary of the results obtained from the multi-substrate functional screens. Results were monitored after overnight incubation at $37^{\circ} \mathrm{C}$ followed by prolonged parallel incubation at 20 and $55^{\circ} \mathrm{C}$ temperatures.
The overall development of a clearing zone around the colony is taken as an indication of proteolytic activity (plus signs)

\begin{tabular}{|c|c|c|c|c|c|c|c|c|}
\hline \multirow[t]{2}{*}{ Fosmid ID } & \multicolumn{7}{|c|}{ Clearing zone on agar-based screens } & \multirow[t]{2}{*}{ Total } \\
\hline & Skim milk & Fish gelatin & Zein & Gluten & Bone meal & Feather meal & Blood meal & \\
\hline TB1 & + & + & + & + & + & + & + & 7 \\
\hline TB2 & + & + & + & + & + & + & + & 7 \\
\hline TB3 & + & + & + & + & + & + & + & 7 \\
\hline TB4 & + & - & - & + & - & - & + & 3 \\
\hline MB1 & + & - & - & - & - & - & - & 1 \\
\hline MB2 & + & - & - & + & - & - & - & 2 \\
\hline MB3 & + & - & - & + & - & - & - & 2 \\
\hline MH1 & + & + & + & + & + & + & + & 7 \\
\hline MH2 & + & + & - & - & - & - & + & 3 \\
\hline MH3 & + & - & - & - & - & - & - & 1 \\
\hline MH4 & + & - & - & - & - & - & - & 1 \\
\hline Total & 11 & 5 & 4 & 7 & 4 & 4 & 6 & \\
\hline
\end{tabular}

The candidates span two serine protease clans (S01, S09) and four metalloproteases clans (M04, M10/12, M20, M42) according to classification by MEROPS, had various length (267-560 amino acids), and their identities to the closest homologous protein sequences ranged from 58.02 to $99.4 \%$ (Table 2). Pfam protease domain coordinates and catalytic residues are depicted for all six candidates in Fig. 2. Analysis of the DNA insert region using RAST and MetaErg (data not shown) revealed affiliation of $\mathrm{MH} 1$ to Alphaproteobacteria and of TB1-TB2-TB3 to Geobacillus, in agreement with the microbial diversity of the corresponding samples from which the libraries derived (Leis et al. 2015; Bargiela et al. 2015).

For each of the six gene candidates, constructs were designed for recombinant expression in $E$. coli. The six protease candidates that were subjected to downstream analysis were given an arbitrary identification number, C1-C6 (Table 2). In two of the candidates, predicted leader sequences were excluded. In one candidate, $\mathrm{C} 5$, the accessory non-protease PDZ domains were removed to reduce protein size (Fig. 2). Using FX-cloning technology, synthetic gene versions were successfully inserted into two different expression vectors, adding either an N-terminal histidine (his) tag or a Cterminal his-tag, to support recombinant, cytoplasmic expression in E. coli, and downstream purification.

\section{Expression and activity assessment of recombinant candidates} confirmed two soluble proteolytic enzymes Recombinant expression of individual genes (Figure S1) was observed for most of the candidates (except C5), in at least one of the two construct variants, with two of them being unambiguously soluble ( $\mathrm{C} 1$ and $\mathrm{C} 2$ ). Activity was assessed for all cleared lysates even in the absence of a clear observation of recombinant proteins, based on the assumption and experience that enzymes might be present in small amount, sufficient to identify activity (Bjerga et al. 2016). Two metalloproteases, C3 and $\mathrm{C} 6$, revealed proteolytic activity, more than 6-fold above the background control after $15 \mathrm{~h}$ incubation on FITC-casein (Fig. 3). A recombinant S8 protease (subtilisin) from $B$. licheniformis, previously used to validate the expression system (Bjerga et al. 2016), showed a similar activity in the experimental conditions. Proteolytic activity was measured for both the N-terminal and C-terminal his-tagged constructs with no significant differences observed (not shown). The four other candidate proteases $(\mathrm{C} 1, \mathrm{C} 2, \mathrm{C} 4$, and $\mathrm{C} 5)$ were not shown to be functional, likely due to lack of expression (C5), poor solubility (C4), or no activity of the soluble protein $(\mathrm{C} 1, \mathrm{C} 2)$.

Both C3 and C6 are zinc-binding metalloproteases belonging to the MA clan, according to the MEROPS classification. They contain a signature HEXXH sequence, shown by crystallographic studies to form a metal-binding motif, and a glutamate, both important for catalysis (Onoda et al. 2009). The C3 protease was present in TB1, TB2, and TB3 and the C6 protease was present in the MH1 clone. The C3 protease is 548residue long with a predicted Peptidase_M4 and a Peptidase_M4_C domains according to Pfam (Fig. 2, Table 2). A leader sequence was predicted at the N-terminus. In addition, auxiliary domains FTP and PepSY were predicted at the N-terminal region of the protease (Fig. 2). A MEROPS search identified the closest homolog as a neutral M4 protease with which it shared $98.5 \%$ sequence identity (Table 2). The C6 
Fig. 1 Functional screen of eleven proteolytic EPI300-T1 ${ }^{\mathrm{R}}$ clones on NA medium supplemented with zein. The plates were grown overnight at 37 ${ }^{\circ} \mathrm{C}$, and for another $48 \mathrm{~h}$ at $20^{\circ} \mathrm{C}$ (top) or $55^{\circ} \mathrm{C}$ (bottom). The formation of clearing zones around the clones is attributed to enzymatic hydrolysis of the zein substrate. Two different nonproteolytic fosmid clones were used as negative background controls. Two blank spots were included to monitor eventual contamination carried on the pin replicator

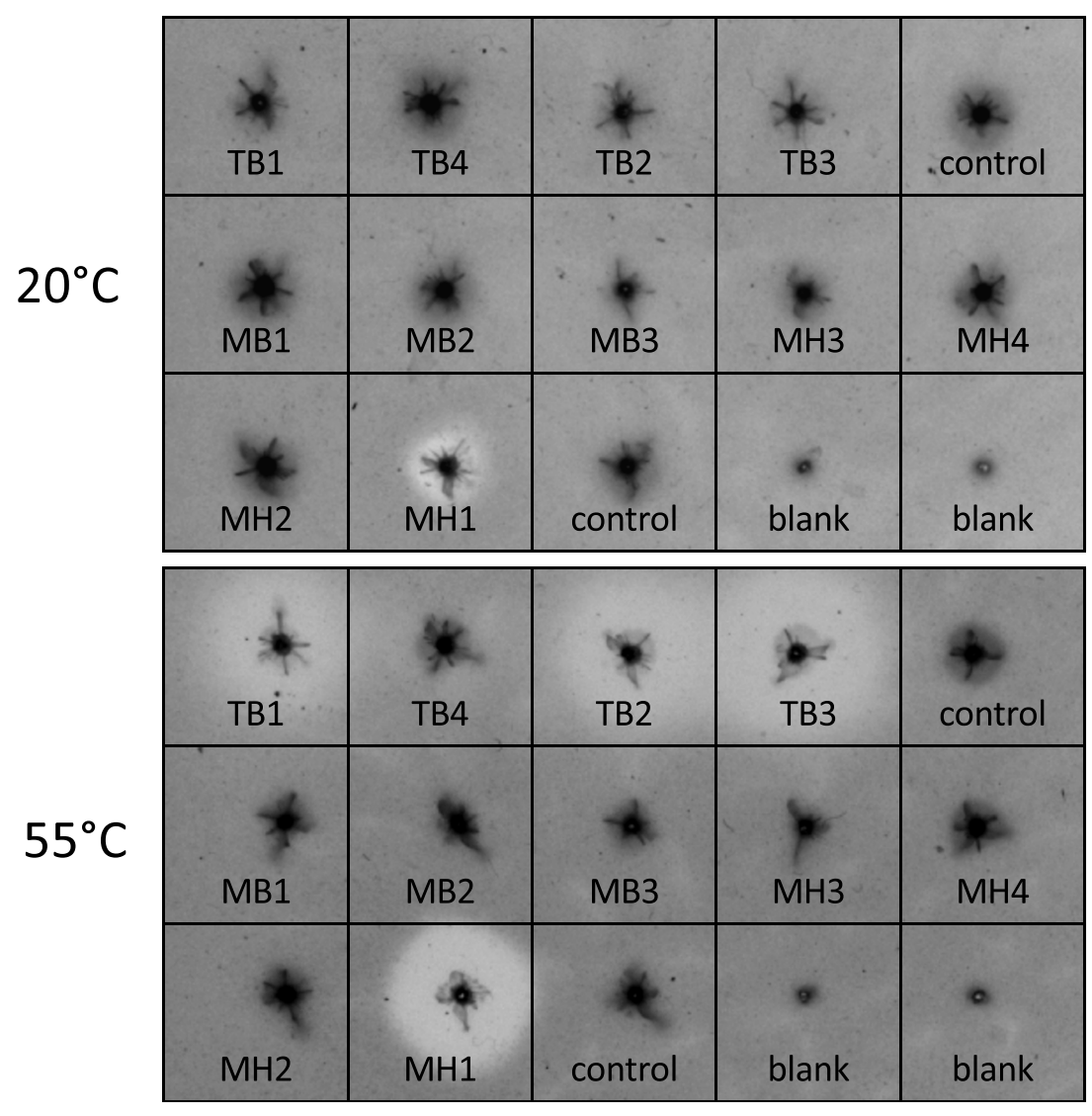

candidate encodes a protease of 289 amino acids with a predicted molecular weight of $32.9 \mathrm{kDa}$ (Fig. 2, Table 2). According to Pfam, the sequence harbors a metalloprotease M12B reprolysin domain across residues 152-229 (Fig. 2). Blast search against the NCBI database identified a homologous metalloprotease sequence which shares a $65 \%$ sequence identity (Table 2 ). A

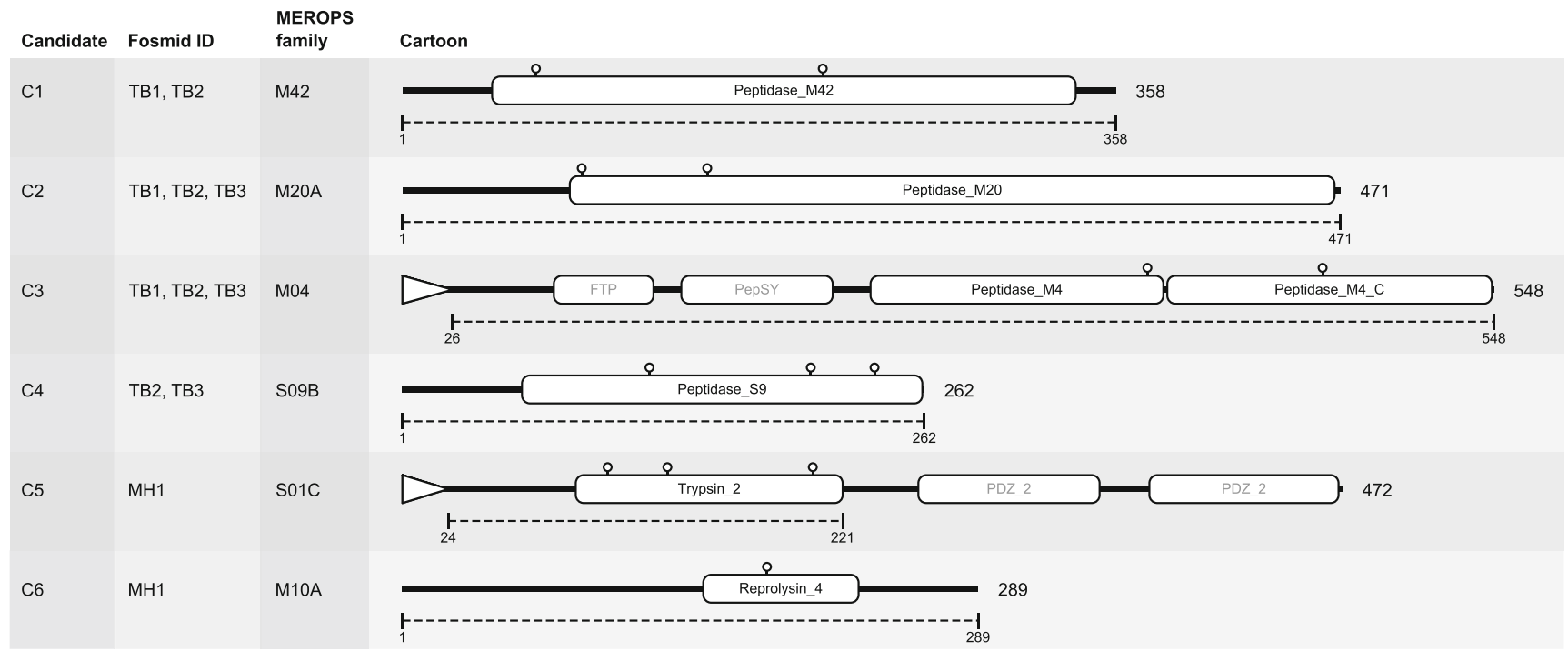

Fig. 2 Cartoon of the six proteases candidates with annotated domains. Leader sequences predicted for candidates $\mathrm{C} 1-\mathrm{C} 6$ are indicated by open triangles at the $\mathrm{N}$-termini. Domains and domain names are annotated from Pfam, and depicted as open rounded rectangles. Sequence lengths (amino acids) are indicated to the right of the cartoons. Catalytic residues are extrapolated from multiple sequence alignments of the 20 closest MEROPS homologs and indicated by hairpins. The dotted lines and associated sequence numbers indicate the regions used in recombinant cloning and expression of individual proteases. Cartoon is drawn to scale 


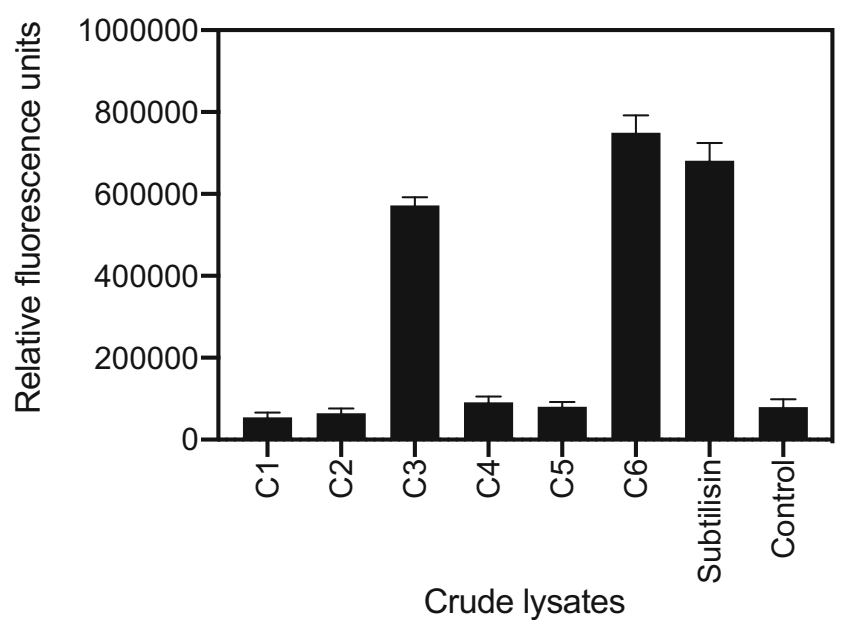

Fig. 3 Proteolytic activity of recombinant protease candidates against FITC-casein. Activity in the E. coli cell lysates after heterologous expression of C-terminal his-tagged enzymes was assessed after $15 \mathrm{~h}$. A recombinant subtilisin from $B$. licheniformis is shown as positive control (subtilisin). The results are presented as total fluorescence from release of FITC and compared to the background, which was a lysate obtained with a clone encoding a non-proteolytic hexapeptide (GSGSGS) in place of the recombinant protease (control). The values are calculated as the average of three technical replicates of two independent experiments. Error bars indicate standard deviation between all six replicates

MEROPS search showed that the closest homolog is a M10 protease from Rhizobium, which is $58 \%$ identical to C6.

Both C3 and C6 proteases were confirmed to have a broadsubstrate range Both protease candidates were tested for proteolytic activity against the same seven proteinaceous substrates that were used in the multi-substrate screen of the fosmids. A clearing halo was revealed for all substrates (Fig. 4), thus confirming that both $\mathrm{C} 3$ and $\mathrm{C} 6$ possess a broadsubstrate range and suggesting that they are likely responsible for the results obtained during the functional screen.

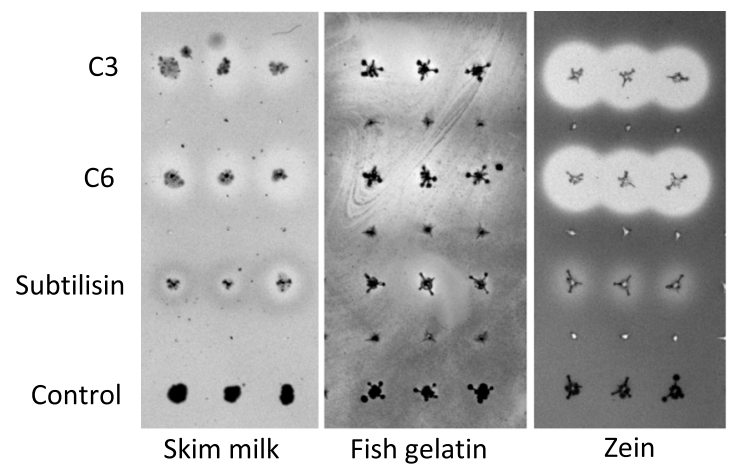

Fig. 4 Proteolytic activity of the recombinant protease candidates against the seven proteinaceous substrates. The $\mathrm{C} 3$ and $\mathrm{C} 6$ candidates were cloned into and expressed recombinantly in E. coli with C-terminal histags. A recombinantly expressed subtilisin using the same expression system was used as positive control and a non-proteolytic hexapeptide (GSGSGS) in place of the recombinant protease was used as background control. The bacterial cultures were grown and induced in LB before

\section{One of the proteases was confirmed to completely hydrolyze zein in a liquid assay}

To assess the zein hydrolyzing capacity of the recombinant $\mathrm{C} 3$ and C6 proteases, the cleared E. coli lysates obtained from heterologous expression of the protease-encoding genes were produced and incubated with zein at two temperatures, 20 and $50{ }^{\circ} \mathrm{C}$. The hydrolysis result after $48 \mathrm{~h}$ incubation (Fig. 5a) was consistent with the observed activities from the screen of the originating fosmid clones on the zein solid agar screens incubated at $55^{\circ} \mathrm{C}$ temperature (Table 3, Fig. 1). Almost complete solubilization of zein was observed at 20 and $50{ }^{\circ} \mathrm{C}$ for the samples containing C6 compared to background (Fig. 5b). Moreover, C6 already showed significant zein hydrolysis after $24 \mathrm{~h}$ incubation at $50^{\circ} \mathrm{C}$ and marginal hydrolysis of zein at 20 ${ }^{\circ} \mathrm{C}$ (not shown). The $\mathrm{C} 3$ and the recombinant $B$. licheniformis subtilisin rendered only marginal hydrolysis of zein at both temperature conditions tested, comparable to the background. A parallel experiment at $\mathrm{pH} 7.5$ gave the same results (not shown).

Recombinant C6 protease, purified to $99 \%$ purity (Figure S2), displayed highest activity against zein at a range of $\mathrm{pH}$ from 9.0 to 11.0 , with a maximum at $\mathrm{pH} 10$ (Fig. 6a). Further, C6 protease showed significant hydrolyzing activity against zein at all temperatures tested $\left(20-70^{\circ} \mathrm{C}\right)$ with a maximum observed at $45^{\circ} \mathrm{C}$ (Fig. 6b).

\section{Discussion}

Reports on new proteases identified by functional metagenomics from the last two decades encompass a limited substrate range and mild screening conditions (Table 1 and references therein). Altogether, these studies have reported 23 
a

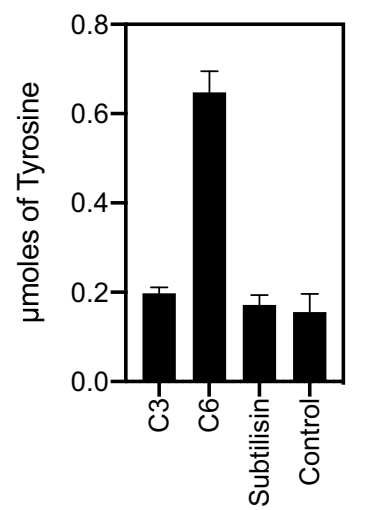

b

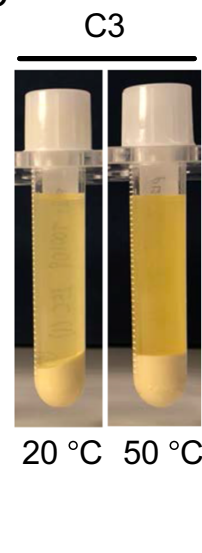

Fig. 5 Proteolytic activity of recombinant protease candidates against insoluble zein. a Hydrolysis of zein is shown by addition of cleared lysates containing recombinant $\mathrm{C} 3, \mathrm{C} 6$, the $B$. licheniformis subtilisin, and a background obtained with a clone encoding a non-proteolytic hexapeptide (GSGSGS) in place of the recombinant protease (control). The results are presented as $\mu$ moles of L-tyrosine available after $48 \mathrm{~h}$ hydrolysis of zein based on a standard curve of L-tyrosine and compared
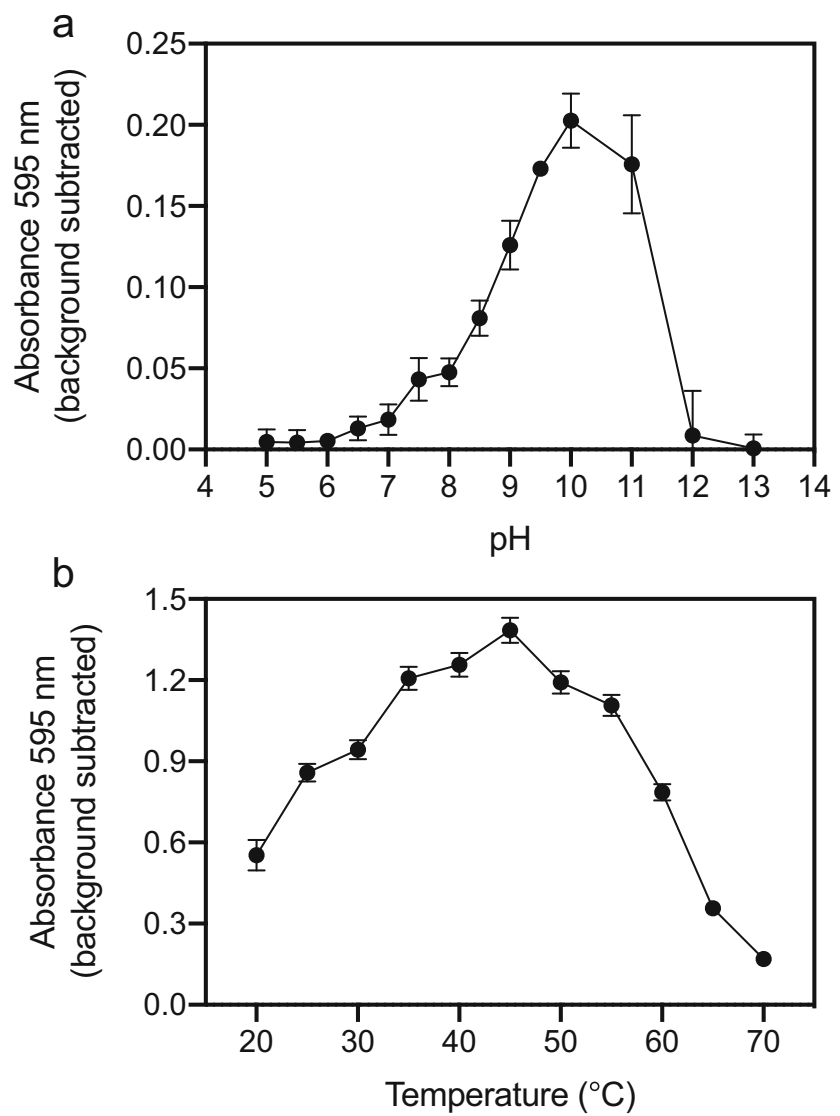

Fig. 6 Optimal parameters for activity for the purified C6 protease. Profiles for $\mathrm{pH}$ (a) and temperature (b) were calculated using zein across a $\mathrm{pH}$ range from 5.0 to $13.0\left(2 \mathrm{~h}\right.$ incubation at $\left.50^{\circ}\right)$ and a temperature range from 20 to $70{ }^{\circ} \mathrm{C}(24 \mathrm{~h}$ incubation at $\mathrm{pH} 10.0)$. The standard deviation was calculated from three technical replicates
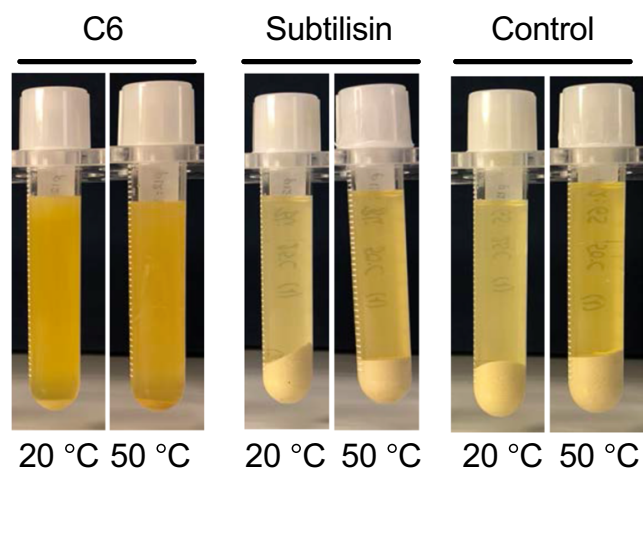

$20{ }^{\circ} \mathrm{C} 50{ }^{\circ} \mathrm{C} \quad 20^{\circ} \mathrm{C} 50^{\circ} \mathrm{C}$ to the background. The values are calculated as the average of three technical replicates of two independent experiments. Error bars indicate standard deviation between all six replicates. b Solubilization of zein by the $\mathrm{C} 6$ protease is clearly visible after a $48 \mathrm{~h}$ incubation at $50{ }^{\circ} \mathrm{C}$, as revealed by the reduction of the pellet and the increased opacity of the solution

proteases, with a clear bias toward serine proteases, and most ignoring desirable attributes for industrial application. This landscape supports the notion that current standard screening techniques do not suffice for accessing the full repertoire of microbial proteases with potential for industrial applications (Morris and Marchesi 2015). In line with other similar setups for other enzyme classes (Schückel et al. 2016; Maruthamuthu et al. 2016), our study demonstrates the successful use of a two-step screen, and we show that other substrates and conditions for activity assessment may be useful to retrieve new enzymes with broad-substrate range and moderately high temperature stability. Of the eleven proteolytic clones that presented clearing zones in the first screen on SMA plates (Table 3), several did not show hydrolysis in any of the other substrates in the second screen. This discrepancies may indicate that these clones contain hydrolases that are active on other constituents than casein in skim milk, as it has previously been described (Jones et al. 2007). Despite its limitations, we validated skim milk/casein as an easily accessible, soluble and useful substrate for an initial screen. A second screening step of multiple substrates may thus be used to filter out nonproteolytic candidates or proteases with a narrow substrate range. Moreover, the six candidate proteases identified with broadest substrate range belong to two different clans and none of them is related to the frequently found S08 subtilisin type (Table 1, Table 2). The approach presented here may assist to focus the enzyme discovery effort and efficiently eliminate resource-demanding examination of enzymes with limited value for downstream research and applications.

All the mixed-genomic and metagenomic libraries screened originate from marine environments (Table 2). 
However, none of the proteinaceous substrates chosen, except for cold water fish gelatin, are in principle relevant for the marine environment. This approach is therefore able to discover new enzymes independently of the metagenomic origin toward the activity that is sought. Thus, our study shows the potential of marine bioprospecting to identify new unexplored sequences, in line with previous reports (Ferrer et al. 2019).

Most of the proteinaceous substrates used in this study are insoluble and unable to enter the bacterial E. coli cell. The generation of hydrolytic clearing zones relies therefore on the spontaneous lysis of cells to release the enzyme (Tasse et al. 2010; Cárcel-Márquez et al. 2019) or the ability of the surrogate host to export the enzymes coded in the metagenomic DNA. In our approach, an initial incubation at the optimal growth temperature of the host $\left(37^{\circ} \mathrm{C}\right)$ allows colony formation and expression from the metagenomic DNA using E. coli's transcription/translation machinery. Subsequent incubation at lower temperature $\left(20^{\circ} \mathrm{C}\right)$ allows clearing zone formation to proceed, while growth is stalled or slowed down. This strategy is typically used in functional metagenomic surveys for proteases (Table 1) to minimize masking effects due to overgrowth and facilitates the perception of hydrolytic activity (Molitor et al. 2020). However, prolonged parallel incubation at $55{ }^{\circ} \mathrm{C}$ accelerates the lysis of cells within the colony and the release of their contents to the medium, thus, increasing the sensitivity of the assay by bypassing secretion routes. This may be particularly true for the MH1 clone, carrying the C6 protease, for which no signal peptide was predicted (Fig. 2) and that repeatedly showed enlarged hydrolytic clearing zones after the prolonged $55^{\circ} \mathrm{C}$ incubation step on the substrates it acted on (Fig. 1, Table 3). Increased incubation temperature might also have improved both the solubility of the proteinaceous substrate and the diffusion of the protease.

The method served to identify robust proteases with broadsubstrate range, including two proteases ( $\mathrm{C} 3$ and $\mathrm{C} 6)$ confirmed to hydrolyze all seven proteinaceous substrates tested in the solid media (Fig. 4).

Zein is of particular interest, as only a limited number of zein-degrading proteases have been reported, all originating from Bacillus strains (B. licheniformis, thermoproteolyticus, amyloliquefaciens, subtilis, and pumilus), the fungus Aspergillus oryzae and plants (de Barros and Larkins 1990; Belles et al. 2000; Ramakrishna and Rao 2005; Miyaji et al. 2006). However, the zein-degrading C6 protease (both in solid and liquid assay formats) here reported originate from a bacterium largely neglected for their capacity to degrade zein. Indeed, the insert DNA of the fosmid clone MH1, containing C6 protease, is affiliated to Rhodobacteraceae, a common dweller of marine sediments (Pohlner et al. 2019). The DNA in fosmid clone $\mathrm{MH} 1$ originates from a shallow polluted marine sediment and it is likely represented by psychrophiles and mesophiles (Yakimov et al. 2005; Bargiela et al. 2015). Native enzymes from mesophiles can still show temperature tolerance (Veith et al. 2012), which appears to be the case for the C6 protease (Fig. 6). A presumptive thermal-tolerance was also noticed for the $\mathrm{C} 3$ protease in solid medium screens. The C3-carrying fosmid clones originate from a collection of thermophilic isolates (Hussein et al. 2015), and the insert DNA sequence affiliated to the Geobacillus genus, a known thermophile. Although the $\mathrm{C} 3$ protease has a predicted signal peptide for secretion through the ubiquitous Sec pathway (Fig. 1, Fig. 2), hydrolytic activity for the C3-carrying fosmid clones is likely due to cell lysis, as clearing zones appear after prolonged incubations at $37{ }^{\circ} \mathrm{C}$ (initial screen on skim milk) and $55^{\circ} \mathrm{C}$ (all substrates). Although further biochemical characterization of the $\mathrm{C} 3$ protease will be needed to know its exact temperature range of activity, it appears in our study to be moderately thermostable in the solid medium screens. To conclude, this study reports proteases with activity against zein identified with functional metagenomics and demonstrates the power of using multiple proteinaceous substrates to focus efforts in functional metagenomics. In addition to that, adding various temperatures to the two-step solid substrate screen method herein reported may thus, reveal the temperature tolerance of enzymes degrading protein-based substrates.

Although phylogenetic, structural and mechanistic characterization of the $\mathrm{C} 6$ protease will be needed to determine its functional novelty; the observed hydrolysis and solubilization of zein at $50-55^{\circ} \mathrm{C}$ (Fig. 1, Fig. 5) supports its applicability and robustness in industrial processes. Its alkaline $\mathrm{pH}$ profile (Fig. 6b) is distinct from those of previously reported neutral zein-hydrolytic proteases (de Barros and Larkins 1990; Belles et al. 2000; Murakami and Hirata 2000; Ramakrishna and Rao 2005; Miyaji et al. 2006). Subtilisins, and more recently, thermolysins, have been typically used in zein hydrolysis (Murakami and Hirata 2000; Miyaji et al. 2006), based on their commercial availability, but with limited success. In contrast to previous reports using Alcalase ${ }^{\circledR}$ (alkaline subtilisin from $B$. licheniformis) and Neutrase ${ }^{\circledR}$ (neutral thermolysin from B. amyloliquefaciens) (Liang et al. 2018), neither the $B$. licheniformis subtilisin nor the thermolysin-like $\mathrm{C} 3$ protease rendered activity in our batch zein hydrolysis experiments (Fig. 5). Although we establish that all three enzymes were capable of hydrolyzing casein over $15 \mathrm{~h}$ (Fig. 3), the reason why subtilisin and $\mathrm{C} 3$ fail in hydrolyzing zein may be explained by our relatively low load of recombinant enzyme to substrate compared to previous reports using commercial enzymes. Although no activity was detected with the other cloned proteases from the TB metagenomic fosmid clones, a cumulative effect during the hydrolysis of zein in the secondary screen step cannot be ruled out. The C6 protease, however, complements the existing catalog of zein-degrading enzymes and may deserve a more exhaustive analysis in industrial zein hydrolysis. 
The resolution of classical functional screening strategies for proteases from environmental metagenomic libraries can be increased. The inclusion of a secondary screen with several targeted proteinaceous substrates and industry mimicking conditions can extend its potential for the discovery of new enzymes with industrial relevance. The two-step multi-substrate approach herein described led to distinctive discrimination of enzymes with broad-substrate scopes, including the identification of two thermostable proteases, whereof one readily solubilized zein. This is the first metagenomederived protease with proven hydrolyzing activity against the insoluble zein, also from a microorganism whose ability to degrade zein was unknown. Altogether, the new functional screening platform can be beneficial to direct future bioprospecting campaigns of proteases toward specific industry applications, thus limiting costly and time-consuming experimental validation to an exclusive set of candidates.

Supplementary Information The online version contains supplementary material available at https://doi.org/10.1007/s00253-021-11235-9.

Acknowledgements We want to thank Professor Mohamed Jebbar (University of Brest, CNRS, IFREMER), Professor Peter N. Golyshin (Bangor University), and Michail M. Yakimov (Institute for Biological Resources and Marine Biotechnology, IRBIM-CNR) for the kind gift of bio-resources (isolates and pCC1FOS libraries). The authors gratefully acknowledge Peter N. Golyshin for fosmid sequencing and Jan Vester for helpful advice.

Author contribution AGM, MF, and GEKB conceived and designed the research. AGM, YD, JN, and DA conducted the experiments. PP contributed with data analysis and graphics. AGM wrote the manuscript with input from GEKB, PP, and MF. All authors reviewed and approved the manuscript.

Funding Open access funding provided by NORCE Norwegian Research Centre AS. This work was funded by "INMARE" under the European Union's Horizon 2020 programme (grant agreement no. 634486) and the Marine Biotechnology ERA-NET and from the Ministerio de Economía y Competitividad, Ministerio de Ciencia, Innovación y Universidades, Agencia Estatal de Investigación, Fondo Europeo de Desarrollo Regional (grants PCIN-2017-078 and BIO201785522-R).

Availability of data and material Metagenomic fosmid DNA sequences have been deposited in GenBank under BioSample accession numbers: SAMN14533297 (MH1) and SAMN14533298 (TB2).

Code availability Not applicable.

\section{Declarations}

Ethics approval Not applicable.

Consent for publication All authors have approved the submitted version and give consent for publication.

Conflict of interest The authors declare no competing interests.

\section{References}

Altschul SF, Gish W, Miller W, Myers EW, Lipman DJ (1990) Basic local alignment search tool. J Mol Biol 215:403-410. https://doi. org/10.1016/S0022-2836(05)80360-2

Anderson TJ, Lamsal BP (2011) REVIEW: zein extraction from corn, corn products, and coproducts and modifications for various applications: a review. Cereal Chem J 88:159-173. https://doi.org/10. 1094/CCHEM-06-10-0091

Apolinar-Hernández MM, Peña-Ramírez YJ, Pérez-Rueda E, CantoCanché BB, De los Santos-Briones C, O’Connor-Sánchez A (2016) Identification and in silico characterization of two novel genes encoding peptidases S8 found by functional screening in a metagenomic library of Yucatán underground water. Gene 593: 154-161. https://doi.org/10.1016/j.gene.2016.08.009

Aziz RK, Bartels D, Best AA, DeJongh M, Disz T, Edwards RA, Formsma K, Gerdes S, Glass EM, Kubal M, Meyer F, Olsen GJ, Olson R, Osterman AL, Overbeek RA, McNeil LK, Paarmann D, Paczian T, Parrello B, Pusch GD, Reich C, Stevens R, Vassieva O, Vonstein V, Wilke A, Zagnitko O (2008) The RAST Server: rapid annotations using subsystems technology. BMC Genomics 9:75. https://doi.org/10.1186/1471-2164-9-75

Bargiela R, Mapelli F, Rojo D, Chouaia B, Tornés J, Borin S, Richter M, Del Pozo MV, Cappello S, Gertler C, Genovese M, Denaro R, Martínez-Martínez M, Fodelianakis S, Amer RA, Bigazzi D, Han X, Chen J, Chernikova TN, Golyshina OV, Mahjoubi M, Jaouanil A, Benzha F, Magagnini M, Hussein E, Al-Horani F, Cherif A, Blaghen M, Abdel-Fattah YR, Kalogerakis N, Barbas C, Malkawi HI, Golyshin PN, Yakimov MM, Daffonchio D, Ferrer M (2015) Bacterial population and biodegradation potential in chronically crude oil-contaminated marine sediments are strongly linked to temperature. Sci Rep 5:11651. https://doi.org/10.1038/srep11651

Belles AM, Montville TJ, Wasserman BP (2000) Enzymatic removal of zeins from the surface of maize starch granules. J Ind Microbiol Biotechnol 24:71-74. https://doi.org/10.1038/sj.jim.2900767

Biver S, Portetelle D, Vandenbol M (2013) Characterization of a new oxidant-stable serine protease isolated by functional metagenomics. Springerplus 2:410. https://doi.org/10.1186/2193-1801-2-410

Bjerga GEK, Arsin H, Larsen Ø, Puntervoll P, Kleivdal HT (2016) A rapid solubility-optimized screening procedure for recombinant subtilisins in E. coli. J Biotechnol 222:38-46. https://doi.org/10.1016/J. JBIOTEC.2016.02.009

Cárcel-Márquez J, Flores A, Martín-Cabello G, Santero E, Camacho EM (2019) Development of an inducible lytic system for functional metagenomic screening. Sci Rep 9:3887. https://doi.org/10.1038/ s41598-019-40470-4

Chapman J, Ismail A, Dinu C (2018) Industrial applications of enzymes: recent advances, techniques, and outlooks. Catalysts 8:238. https:// doi.org/10.3390/catal 8060238

de Barros EG, Larkins BA (1990) Purification and characterization of zein-degrading proteases from endosperm of germinating maize seeds. Plant Physiol 94:297-303. https://doi.org/10.1104/pp.94.1. 297

Devi SG, Fathima AA, Sanitha M, Iyappan S, Curtis WR, Ramya M (2016) Expression and characterization of alkaline protease from the metagenomic library of tannery activated sludge. J Biosci Bioeng 122:694-700. https://doi.org/10.1016/j.jbiosc.2016.05.012

Díaz-Gómez JL, Ortíz-Martínez M, Aguilar O, García-Lara S, CastorenaTorres F (2018) Antioxidant activity of zein hydrolysates from Zea species and their cytotoxic effects in a hepatic cell culture. Molecules 23. https://doi.org/10.3390/molecules23020312

Dong X, Strous M (2019) An integrated pipeline for annotation and visualization of metagenomic contigs. Front Genet 10:999. https:// doi.org/10.3389/fgene.2019.00999 
Ferrer M, Martínez-Martínez M, Bargiela R, Streit WR, Golyshina OV, Golyshin PN (2016) Estimating the success of enzyme bioprospecting through metagenomics: current status and future trends. Microb Biotechnol 9:22-34. https://doi.org/10.1111/17517915.12309

Ferrer M, Méndez-García C, Bargiela R, Chow J, Alonso S, GarcíaMoyano A, Bjerga GEK, Steen IH, Schwabe T, Blom C, Vester J, Weckbecker A, Shahgaldian P, de Carvalho CCCR, Meskys R, Zanaroli G, Glöckner FO, Fernández-Guerra A, Thambisetty S, de la Calle F, Golyshina OV, Yakimov MM, Jaeger K-E, Yakunin AF, Streit WR, McMeel O, Calewaert J-B, Tonné N, Golyshin PN, INMARE Consortium TI (2019) Decoding the ocean's microbiological secrets for marine enzyme biodiscovery. FEMS Microbiol Lett 366. https://doi.org/10.1093/femsle/fny285

Finn RD, Bateman A, Clements J, Coggill P, Eberhardt RY, Eddy SR, Heger A, Hetherington K, Holm L, Mistry J, Sonnhammer ELL, Tate J, Punta M (2014) Pfam: the protein families database. Nucleic Acids Res 42:D222-D230. https://doi.org/10.1093/nar/ gkt1223

Global Protease Market Report (2019) History and Forecast 2014-2025, Breakdown Data by Manufacturers, Key Regions, Types and Application

Gong B-L, Mao R-Q, Xiao Y, Jia M-L, Zhong X-L, Liu Y, Xu P-L, Li G (2017) Improvement of enzyme activity and soluble expression of an alkaline protease isolated from oil-polluted mud flat metagenome by random mutagenesis. Enzym Microb Technol 106:97-105. https://doi.org/10.1016/j.enzmictec.2017.06.015

Healy FG, Ray RM, Aldrich HC, Wilkie AC, Ingram LO, Shanmugam KT (1995) Direct isolation of functional genes encoding cellulases from the microbial consortia in a thermophilic, anaerobic digester maintained on lignocellulose. Appl Microbiol Biotechnol 43:667674. https://doi.org/10.1007/BF00164771

Hussein AH, Lisowska BK, Leak DJ (2015) The genus Geobacillus and their biotechnological potential. In: Advances in applied microbiology. Elsevier Academic Press Inc, pp 1-48

Iqbal HA, Craig JW, Brady SF (2014) Antibacterial enzymes from the functional screening of metagenomic libraries hosted in Ralstonia metallidurans. FEMS Microbiol Lett 354:19-26. https://doi.org/10. 1111/1574-6968.12431

Jiang C, Zhang L, Li F, Meng C, Zeng R, Deng J, Shen P, Ou Q, Wu B (2017) Characterization of a metagenome-derived protease from contaminated agricultural soil microorganisms and its random mutagenesis. Folia Microbiol (Praha) 62:499-508. https://doi.org/10. 1007/s12223-017-0522-y

Jin D, Liu X, Zheng X, Wang X, He J (2016) Preparation of antioxidative corn protein hydrolysates, purification and evaluation of three novel corn antioxidant peptides. Food Chem 204:427-436. https://doi.org/ 10.1016/J.FOODCHEM.2016.02.119

Jones BV, Sun F, Marchesi JR (2007) Using skimmed milk agar to functionally screen a gut metagenomic library for proteases may lead to false positives. Lett Appl Microbiol 45:418-420. https:// doi.org/10.1111/j.1472-765X.2007.02202.x

Kasaai MR (2018) Zein and zein-based nano-materials for food and nutrition applications: a review. Trends Food Sci Technol 79:184-197. https://doi.org/10.1016/j.tifs.2018.07.015

Kennedy J, O'Leary ND, Kiran GS, Morrissey JP, O'Gara F, Selvin J, Dobson ADW (2011) Functional metagenomic strategies for the discovery of novel enzymes and biosurfactants with biotechnological applications from marine ecosystems. J Appl Microbiol 111: 787-799. https://doi.org/10.1111/j.1365-2672.2011.05106.x

Kong B, Xiong YL (2006) Antioxidant activity of zein hydrolysates in a liposome system and the possible mode of action. J Agric Food Chem 54:6059-6068. https://doi.org/10.1021/jf060632q

Kong X, Zhou H, Qian H (2007) Enzymatic hydrolysis of wheat gluten by proteases and properties of the resulting hydrolysates. Food
Chem 102:759-763. https://doi.org/10.1016/J.FOODCHEM.2006. 06.062

Lee MH, Lee S-W (2013) Bioprospecting potential of the soil metagenome: novel enzymes and bioactivities. Genomics Inform 11:114-120. https://doi.org/10.5808/GI.2013.11.3.114

Lee D-G, Jeon JH, Jang MK, Kim NY, Lee JH, Lee J-H, Kim S-J, Kim GD, Lee S-H (2007) Screening and characterization of a novel fibrinolytic metalloprotease from a metagenomic library. Biotechnol Lett 29:465-472. https://doi.org/10.1007/s10529-006-9263-8

Leis B, Heinze S, Angelov A, Pham VTT, Thürmer A, Jebbar M, Golyshin PN, Streit WR, Daniel R, Liebl W (2015) Functional screening of hydrolytic activities reveals an extremely thermostable cellulase from a deep-sea archaeon. Front Bioeng Biotechnol 3:95. https://doi.org/10.3389/fbioe.2015.00095

Li Q (2019) Progress in microbial degradation of feather waste. Front Microbiol 10:2717. https://doi.org/10.3389/fmicb.2019.02717

Liang Q, Chalamaiah M, Ren X, Ma H, Wu J (2018) Identification of new anti-inflammatory peptides from zein hydrolysate after simulated gastrointestinal digestion and transport in Caco-2 cells. J Agric Food Chem 66:1114-1120. https://doi.org/10.1021/acs.jafc. $7 \mathrm{~b} 04562$

Marchler-Bauer A, Lu S, Anderson JB, Chitsaz F, Derbyshire MK, DeWeese-Scott C, Fong JH, Geer LY, Geer RC, Gonzales NR, Gwadz M, Hurwitz DI, Jackson JD, Ke Z, Lanczycki CJ, Lu F, Marchler GH, Mullokandov M, Omelchenko MV, Robertson CL, Song JS, Thanki N, Yamashita RA, Zhang D, Zhang N, Zheng C, Bryant SH (2011) CDD: a Conserved Domain Database for the functional annotation of proteins. Nucleic Acids Res 39:D225D229. https://doi.org/10.1093/nar/gkq1189

Martínez-Martínez M, Coscolín C, Santiago G, Chow J, Stogios PJ, Bargiela R, Gertler C, Navarro-Fernández J, Bollinger A, Thies S, Méndez-García C, Popovic A, Brown G, Chernikova TN, GarcíaMoyano A, Bjerga GEK, Pérez-García P, Hai T, Del Pozo MV, Stokke R, Steen IH, Cui H, Xu X, Nocek BP, Alcaide M, Distaso M, Mesa V, Peláez AI, Sánchez J, Buchholz PCF, Pleiss J, Fernández-Guerra A, Glöckner FO, Golyshina OV, Yakimov MM, Savchenko A, Jaeger K-E, Yakunin AF, Streit WR, Golyshin PN, Guallar V, Ferrer M, The INMARE Consortium TI (2018) Determinants and prediction of esterase substrate promiscuity patterns. ACS Chem Biol 13:225-234. https://doi.org/10.1021/ acschembio.7b00996

Maruthamuthu M, Jiménez DJ, Stevens P, van Elsas JD (2016) A multisubstrate approach for functional metagenomics-based screening for (hemi)cellulases in two wheat straw-degrading microbial consortia unveils novel thermoalkaliphilic enzymes. BMC Genomics 17:86. https://doi.org/10.1186/s12864-016-2404-0

Maurer K-H (2004) Detergent proteases. Curr Opin Biotechnol 15:330 334. https://doi.org/10.1016/J.COPBIO.2004.06.005

Mistry VV (2006) Chymosin in cheese making. In: Food biochemistry and food processing. Blackwell Publishing, Ames, pp 241-252

Miyaji T, Otta Y, Nakagawa T, Watanabe T, Niimura Y, Tomizuka N (2006) Purification and molecular characterization of subtilisin-like alkaline protease BPP-A from Bacillus pumilus strain MS-1. Lett Appl Microbiol 42:242-247. https://doi.org/10.1111/j.1472-765X. 2005.01851.x

Molitor R, Bollinger A, Kubicki S, Loeschcke A, Jaeger K, Thies S (2020) Agar plate-based screening methods for the identification of polyester hydrolysis by Pseudomonas species. Microb Biotechnol 13:274-284. https://doi.org/10.1111/1751-7915.13418

Morris LS, Marchesi JR (2015) Current functional metagenomic approaches only expand the existing protease sequence space, but does not presently add any novelty to it. Curr Microbiol 70:19-26. https:// doi.org/10.1007/s00284-014-0677-6

Morris LS, Evans J, Marchesi JR (2012) A robust plate assay for detection of extracellular microbial protease activity in metagenomic 
screens and pure cultures. J Microbiol Methods 91:144-146. https:// doi.org/10.1016/J.MIMET.2012.08.006

Murakami Y, Hirata A (2000) Novel process for enzymatic hydrolysis of proteins in an aqueous two-phase system for the production of peptide mixture. Prep Biochem Biotechnol 30:31-37. https://doi.org/10. 1080/10826060008544942

Neveu J, Regeard C, DuBow MS (2011) Isolation and characterization of two serine proteases from metagenomic libraries of the Gobi and Death Valley deserts. Appl Microbiol Biotechnol 91:635-644. https://doi.org/10.1007/s00253-011-3256-9

Ngara TR, Zhang H (2018) Recent advances in function-based metagenomic screening. Genomics Proteomics Bioinformatics 16: 405-415. https://doi.org/10.1016/J.GPB.2018.01.002

Niehaus F, Gabor E, Wieland S, Siegert P, Maurer KH, Eck J (2011) Enzymes for the laundry industries: tapping the vast metagenomic pool of alkaline proteases. Microb Biotechnol 4:767-776. https:// doi.org/10.1111/j.1751-7915.2011.00279.x

Nielsen H (2017) Predicting secretory proteins with SignalP. Humana Press, New York, pp 59-73

Onoda A, Suzuki T, Ishizuka H, Sugiyama R, Ariyasu S, Yamamura T (2009) Minimal motif peptide structure of metzincin clan zinc peptidases in micelles. J Pept Sci 15:832-841. https://doi.org/10.1002/ psc. 1184

Pal GK, Suresh PV (2016) Microbial collagenases: challenges and prospects in production and potential applications in food and nutrition. RSC Adv 6:33763-33780. https://doi.org/10.1039/C5RA23316J

Pessoa TBA, Rezende RP, Marques E d LS, Pirovani CP, dos Santos TF, dos Santos Gonçalves AC, Romano CC, Dotivo NC, Freitas ACO, Salay LC, Dias JCT (2017) Metagenomic alkaline protease from mangrove sediment. J Basic Microbiol 57:962-973. https://doi. org/10.1002/jobm.201700159

Philipps-Wiemann P (2018) Proteases - animal feed. Enzym Hum Anim Nutr:279-297. https://doi.org/10.1016/B978-0-12-805419-2. 00014-9

Pohlner M, Dlugosch L, Wemheuer B, Mills H, Engelen B, Reese BK (2019) The majority of active Rhodobacteraceae in marine sediments belong to uncultured genera: a molecular approach to link their distribution to environmental conditions. Front Microbiol 10: 659. https://doi.org/10.3389/fmicb.2019.00659

Popovic A, Hai T, Tchigvintsev A, Hajighasemi M, Nocek B, Khusnutdinova AN, Brown G, Glinos J, Flick R, Skarina T, Chernikova TN, Yim V, Brüls T, Le Paslier D, Yakimov MM, Joachimiak A, Ferrer M, Golyshina OV, Savchenko A, Golyshin PN, Yakunin AF (2017) Activity screening of environmental metagenomic libraries reveals novel carboxylesterase families. Sci Rep 7:44103. https://doi.org/10.1038/srep44103

Pushpam P, Rajesh T, Gunasekaran P (2011) Identification and characterization of alkaline serine protease from goat skin surface metagenome. AMB Express 1:3. https://doi.org/10.1186/21910855-1-3

Ramakrishna V, Rao PR (2005) Purification of acidic protease from the cotyledons of germinating Indian bean (Dolichos lablab L. var lignosus) seeds. Afr J Biotechnol 4:703-707. https://doi.org/10. 3923/biotech.2005.365.369
Rawlings ND, Barrett AJ, Thomas PD, Huang X, Bateman A, Finn RD (2018) The MEROPS database of proteolytic enzymes, their substrates and inhibitors in 2017 and a comparison with peptidases in the PANTHER database. Nucleic Acids Res 46:D624-D632. https://doi.org/10.1093/nar/gkx1134

Schückel J, Kračun SK, Willats WGT (2016) High-throughput screening of carbohydrate-degrading enzymes using novel insoluble chromogenic substrate assay kits. J Vis Exp. https://doi.org/10.3791/54286

Sun J, Li P, Liu Z, Huang W, Mao X (2020) A novel thermostable serine protease from a metagenomic library derived from marine sediments in the East China Sea. Appl Microbiol Biotechnol 104:9229-9238. https://doi.org/10.1007/s00253-020-10879-3

Tang X, He Z, Dai Y, Xiong YL, Xie M, Chen J (2010) Peptide fractionation and free radical scavenging activity of zein hydrolysate. $\mathrm{J}$ Agric Food Chem 58:587-593. https://doi.org/10.1021/j99028656

Tasse L, Bercovici J, Pizzut-Serin S, Robe P, Tap J, Klopp C, Cantarel BL, Coutinho PM, Henrissat B, Leclerc M, Doré J, Monsan P, Remaud-Simeon M, Potocki-Veronese G (2010) Functional metagenomics to mine the human gut microbiome for dietary fiber catabolic enzymes. Genome Res 20:1605-1612. https://doi.org/10. 1101/gr.108332.110

Tripathi LP, Sowdhamini R (2008) Genome-wide survey of prokaryotic serine proteases: analysis of distribution and domain architectures of five serine protease families in prokaryotes. BMC Genomics 9:549. https://doi.org/10.1186/1471-2164-9-549

Veith A, Botelho HM, Kindinger F, Gomes CM, Kletzin A (2012) The sulfur oxygenase reductase from the mesophilic bacterium halothiobacillus neapolitanus is a highly active thermozyme. J Bacteriol 194:677-685. https://doi.org/10.1128/JB.06531-11

Waschkowitz T, Rockstroh S, Daniel R (2009) Isolation and characterization of metalloproteases with a novel domain structure by construction and screening of metagenomic libraries. Appl Environ Microbiol 75:2506-2516. https://doi.org/10.1128/AEM.02136-08

Wehrle K, Crowe N, van Boeijen I, Arendt EK (1999) Screening methods for the proteolytic breakdown of gluten by lactic acid bacteria and enzyme preparations. Eur Food Res Technol 209:428-433. https:// doi.org/10.1007/s002170050521

Yakimov MM, Denaro R, Genovese M, Cappello S, D'Auria G, Chernikova TN, Timmis KN, Golyshin PN, Giluliano L (2005) Natural microbial diversity in superficial sediments of Milazzo Harbor (Sicily) and community successions during microcosm enrichment with various hydrocarbons. Environ Microbiol 7:14261441. https://doi.org/10.1111/j.1462-5822.2005.00829.x

Zhang Y, Zhao J, Zeng R (2011) Expression and characterization of a novel mesophilic protease from metagenomic library derived from Antarctic coastal sediment. Extremophiles 15:23-29. https://doi.org/ 10.1007/s00792-010-0332-5

Zhu L, Chen J, Tang X, Xiong YL (2008) Reducing, radical scavenging, and chelation properties of in vitro digests of alcalase-treated zein hydrolysate. J Agric Food Chem 56:2714-2721. https://doi.org/10. 1021/jf703697e

Publisher's note Springer Nature remains neutral with regard to jurisdictional claims in published maps and institutional affiliations. 